Santa Clara University

Scholar Commons

Communication

College of Arts \& Sciences

6-2013

\title{
Co-rumination Partially Mediates the Relationship between Social Support and Emotional Exhaustion among Graduate Students
}

Justin P. Boren

Santa Clara University, jboren@scu.edu

Follow this and additional works at: http://scholarcommons.scu.edu/comm

Part of the Communication Commons

\section{Recommended Citation}

Boren, J. P. (2013). Co-rumination partially mediates the relationship between social support and emotional exhaustion among graduate students. Communication Quarterly, 61(3). 253-267. doi: 10.1080/01463373.2012.751436

http://dx.doi.org/10.1080/01463373.2012.751436

This Article is brought to you for free and open access by the College of Arts \& Sciences at Scholar Commons. It has been accepted for inclusion in Communication by an authorized administrator of Scholar Commons. For more information, please contact rscroggin@scu.edu. 
Co-rumination Partially Mediates the Relationship between Social Support and Emotional Exhaustion among Graduate Students.

\author{
Justin P. Boren \\ Santa Clara University \\ Department of Communication \\ 500 El Camino Real \\ Santa Clara, CA 95053-0277 \\ 408-551-7057, jboren@scu.edu
}

Published in: Communication Quarterly, Vol. 61, Issue 3, 2013, pages 253-267. http://www.tandfonline.com/doi/abs/10.1080/01463373.2012.751436

Author's Note: Justin P. Boren (Ph.D., Arizona State University) is an assistant professor in the department of communication, Santa Clara University. The author would like to thank Drs. Sarah J. Tracy, Paul King, Alice E. Veksler, and two anonymous reviewers for their helpful comments on earlier drafts.

Boren, J. P. (2013). Co-rumination partially mediates the relationship between social support and emotional exhaustion among graduate students. Communication Quarterly, 61(3). 253267. doi: $\underline{10.1080 / 01463373.2012 .751436}$ 


\begin{abstract}
Graduate students regularly report high levels of stress and burnout. Many of those same students utilize social support networks, which can act as stress buffers. This study evaluated excessive negative talk about issues (co-rumination) and its effects on that social-support to burnout (emotional exhaustion) relationship and predicted that co-rumination would act as a suppressor variable. Graduate student volunteers $(N=213)$ reported their levels of social support, co-rumination, and emotional exhaustion. Data indicated that co-rumination did mediate the social support-to-emotional exhaustion relationship on two dimensions. This project purports that, while social support is important, the content of socially-supportive interactions may also be important when attempting to intervene in stressful situations, especially when those interactions involve co-ruminative messages.
\end{abstract}

Keywords: Co-rumination, burnout, social support, graduate school 
Co-rumination Partially Mediates the Relationship between Social Support and Emotional Exhaustion among Graduate Students.

Life as a graduate student can be a stressful experience across the span of academic programs (Heins, Fahey, \& Leiden, 1984; Lundberg, McIntire, \& Creasman, 2008). Across disciplines, graduate students regularly report that they must cope with a variety of stressors that are unique to their role, especially compared to individuals who may enter the workforce immediately following their undergraduate program (Heins et al., 1984). Despite that, graduate students must also cope with stressors commonly reported by members of working organizations including time strain, fear of failure, demanding job requirements, and financial strain. While trying to cope with the stress of school, students must also balance their work, family lives, and teaching requirements (Hammer, Grigsby, \& Woods, 1998). Indeed, attempting to manage school, work, and life can be a stress-inducing experience for many (Hoffman \& Cowan, 2008). Graduate school stressors can lead to a number of negative individual outcomes for students including job burnout (Maslach, Schaufeli, \& Leiter, 2001; Schaufeli \& Bakker, 2004). Therefore, stress requires that graduate students find adequate coping mechanisms.

A large corpus of literature has explored the stress buffering effects of social support in both families and organizations (see Cohen, Underwood, \& Gottlieb, 2000). Social support, which includes communicated messages designed to instill feelings of love, belonging, and acceptance in another person (Zimmermann \& Applegate, 1994), has been seen to mediate the relationship between organizational stressors and job burnout (Schaufeli \& Bakker, 2004) as well as moderate the relationship between physiological stress and burnout (Heaphy \& Dutton, 2008). Despite the positive benefits of social support, researchers have found that some individuals may engage in negative and excessive amounts of discussion about their problems in a dyadic setting, 
a behavior labeled co-rumination (Rose, 2002; Rose, Carlson, \& Waller, 2007), which has the potential to increase both psychological and physiological stress (Byrd-Craven, Granger, \& Auer, 2011). The close relationships developed between graduate students could foster this type of excessive problem talk. This investigation explores the idea that co-rumination can suppress some of the positive effects of social support on burnout among graduate students.

\section{Failure at Work: Stress and Burnout}

Burnout is typically described as wearing out at work (Maslach et al., 2001), especially because burnt-out employees feel that they cannot accomplish their daily work tasks. The study of burnout has gained in popularity over the past three decade because it is a specific stressrelated outcome in organizations and is one of the most commonly-reported responses to organizational strain (Maslach et al., 2001). Maslach et al. (2001) defined burnout as "a psychological syndrome in response to chronic interpersonal stressors on the job" (p. 399) and included three dimensions of emotional exhaustion, cynicism (also called depersonalization), and lack of personal accomplishment (Maslach et al., 2001). Moreover, emotional exhaustion is the most notable dimension of burnout, as it is the initial symptom and is considered by many as being the "stress dimension of burnout" (Maslach et al., 2001, p. 403).

Regardless of organizational context, emotional exhaustion typically materializes as feelings of simply being worn-out, tired, or overloaded by too much work, eventually leading toward a cascade of cynicism and inefficacy (Maslach \& Jackson, 1981). While burnout can occur in almost any job, it is more prevalent in service-related fields, seems to be reported higher in workers under the age of 30 , and is most prevalent in workers who must interface directly with customers, patients, or students (Schaufeli \& Bakker, 2004; Smith, 1999). Based on these parameters, those in academia are at a high risk for experiencing burnout (Maslach et al., 2001), 
and the rigors of graduate school invoke the potential for burnout. Considering that graduate students in many universities have heavy research, teaching, class, and grading responsibilities (Hammer et al., 1998), the potential reports of emotional exhaustion may be numerous and could be detrimental to the individual graduate student, the university, and undergraduate students taking classes from a burnt-out graduate teacher.

In addition to the negative organizational or psychological outcomes of emotional exhaustion, many health-related outcomes have been discovered by researchers. For one, burnout has "physiological correlates [that] mirror those found with other indices of prolonged stress" (Maslach et al., 2001, p. 406), especially among those individuals reporting high amounts of emotional exhaustion. Emotional exhaustion tends to be classified as an outcome of a stressful work environment (Maslach, Jackson, \& Leiter, 1997), such as graduate school (Heins et al., 1984). Individuals reporting chronic work stress and emotional exhaustion were more than twice as likely to have heart disease (Chandola, Brunner, \& Marmot, 2006), sleep disturbances resulting from stress hormone imbalance (Pruessner, Hellhamer, \& Kirschbaum, 1999), and reduced cardiovascular and immune functions (Dickerson \& Kemeny, 2004). Clearly, the effects of burnout have severe and potentially dire consequences, both physical and psychological, on the human body.

As discussed above, burnout is manifested through emotional exhaustion, cynicism, and inefficacy. However, employee engagement is the polar opposite of burnout (Schaufeli \& Bakker, 2004) In fact, engaged employees will report lower amounts burnout and fewer health related problems, even with high job demands. Germane to the present investigation, one important element of engagement can be found in the way that individuals support each other in their daily routines through their interactions with one another (Schaufeli \& Bakker, 2004). 
These interactions take place through a communicative framework and have been found to reduce both stress and burnout (Uchida \& Yamasaki, 2008).

\section{Social Support and Co-Rumination}

Social support is a widely-studied organizational variable that moderates the relationship between psychological stress and physiological health (Schaufeli \& Bakker, 2004). Social support is commonly defined with three primary components: support schemata (or mental maps of supportive social network individuals), supportive relationships (or those actual individuals who provide support), and supportive communicative encounters (Pierce, Sarason, \& Sarason, 1996). These three key components of the supportive process are critical to understanding how individuals give and receive support from others. Social support is a highly communicative transaction between those individuals who want support and those who give support (Burleson, Albrecth, Goldsmith, \& Sarason, 1994; Zimmermann \& Applegate, 1994). In organizations, individuals give and receive informational support (messages to improve knowledge of an issue), instrumental support (co-workers providing each other with physical assistance) and emotional support (interactions to boost morale) to their coworkers (Zimmermann \& Applegate, 1994).

Positive social interactions in organizations may be one of the most important characteristics of both psychological and physiological stress reduction (for a review, see Uchino, 2004) for workers who are reporting high levels of emotional exhaustion (Heaphy \& Dutton, 2008). In fact, in a highly publicized 20-year longitudinal study, increased peer and supervisor support mitigated risk of worker mortality (Shirom, Toker, Alkaly, Jacobson, \& Balicer, 2011). Additionally, researchers have determined that lack of positive workplace social interactions is a risk factor for ischemic heart disease (Eller et al., 2009). In an educational setting, adult learners who felt a sense of positive social support also reported greater self- 
efficacy toward school, especially when those adult learners had strong personal and professional support networks (Lundberg et al., 2008). Similarly, social support moderated the effect between stress and self-confidence, insofar that self-confidence increased because of social support, even for individuals who self-reported a great deal of stress (Rees \& Freeman, 2007).

Clearly, social support helps individuals to cope with their stressful experiences and lack of social support can be potentially dangerous. However, excessive expression of emotion to others can lead to increases in depressive states (Uchida \& Yamasaki, 2008). In fact, emotions can be spread throughout an organization, whereby individuals converge with the emotions of others, defined as an emotional contagion (Hatfield, Cacioppo, \& Rapson, 1993). In an organizational setting, emotional contagions result in lowered communicative effectiveness to stressful events thereby increasing the likelihood of burnout (Miller, Stiff, \& Ellis, 1988). In this sense, the type of emotional expression is important to stress-related outcomes. In a similar way, the type and content of social support is an important variable. Rose (2002) has described this process as co-rumination, or "excessively discussing personal problems within a dyadic relationship" (p. 1830). Co-rumination is related to the psychological concept known as rumination, a negative and constant problem-focus on an issue, thereby increasing the perceived severity of the issue. The distinguishing characteristics of co-rumination are that it is dyadic and communicative. Therefore, co-rumination is characterized by "frequently discussing problems, discussing the same problem repeatedly, mutual encouragement of discussing problems, speculating about problems, and focusing on negative feelings" (Rose, 2002, p. 1830).

As co-rumination involves two people interacting with an inherent goal of mutual support, it is an element of the social support process. While a socially-supportive message may help to solve a problem, a co-ruminative message tends to be more problem-focused with little 
direction toward a solution. In this sense, a co-ruminative interaction may escalate a small problem into something much larger. All organizations are characterized by emotional expression (Sandelands \& Boudens, 2000). In some organizations individuals communicate frequently with each other about their personal and professional problems and may engage in "venting," which is usually seen as an element of emotional catharsis. Similarly, graduate students are in close quarters with their colleagues and rely on each other for social support thereby creating an environment which is conducive to dyadic problem talk and co-rumination.

Co-rumination has both positive and negative benefits. On the dyadic level, it can increase relational closeness but also increases depressive symptomology and anxiety (Rose et al., 2007). Physiologically, co-rumination increases stress hormone production (Byrd-Craven, Geary, Rose, \& Ponzi, 2008) and activation of both the hypothalamic-pituitary-adrenal axis and the sympathetic nervous system, two of the primary systems in the human stress response (ByrdCraven et al., 2011). In an organizational setting, co-rumination was associated with employee adjustment outcome variables relating to abusive supervision (Haggard, Robert, \& Rose, 2011). Taken together, these findings suggest that social support does have many positive outcomes, but co-rumination can have potentially damaging consequences to individuals, thereby indicating that the content of a socially-supportive transaction might be more important than the frequency of supportive encounters.

Since prior research has found that co-rumination increases the amount of stress in individuals while positive social-support interactions tend to reduce the amount of stress, it reasons that co-rumination should reduce some of the beneficial aspects of social-support on emotional exhaustion, acting as a partial mediator in that relationship. Evaluating social support 
or co-rumination alone may not be fruitful, as co-rumination is inherently perceived as a socially-supportive activity. Therefore, the following hypothesis is presented:

H: Among graduate students, co-rumination partially mediates the relationship between social support and frequency and severity of emotional exhaustion.

\section{Method}

This study was reviewed by the author's institutional review board and granted an exemption. All respondents were recruited using volunteer sampling procedures. E-mail messages were sent to a distribution list of all graduate students at a large urban university.

\section{Procedures}

The participants were first asked to agree to an informed consent statement and then asked to complete an online questionnaire using questionpro.com online survey software. The first page of the questionnaire asked for basic demographic information, reported below. After demographic information was collected, each subsequent measure was presented to respondents in random order (measures and items were randomized by the survey system). After participants completed the online questionnaire they were thanked for their participation. No incentives were given for participation.

\section{Participants}

Respondents $(N=213)$ were $152(71.36 \%)$ women and $58(27.23 \%)$ men (with three people declining to indicate their biological sex). The participants ranged in age from $21-58$

years old $(M=29.11, M d n=27.5, S D=6.99$ years $)$. Degree programs included students seeking a Ph.D. or other Doctorate $(n=147,69.01 \%)$, a Master's degree or its equivalent $(n=63$, $29.58 \%)$, and professional degrees $(n=3)$. Respondents were either full time with 6 or more semester units $(n=193,90.61 \%)$ or enrolled in fewer than 6 units $(n=18,8.45 \%)$. On average 
participants reported working 39.09 hours per week on their school responsibilities $(S D=22.67$ hours). Respondents also reported on their assistantship status with 173 (81.22\%) indicating they were currently teaching and/or research assistants (or had a teaching- or research-related job on campus). Those teaching/research assistants worked an average of 22.32 hours $(S D=11.62)$ per week on their teaching responsibilities. Fifty-one of the respondents (23.94\%) indicated that they held a job outside of the university and worked an average of 21.45 hours $(S D=14.95)$ at that outside job. Finally, participants came from a variety of graduate program areas including arts and sciences $(n=61,28.64 \%)$, social sciences $(n=52,24.41 \%)$, engineering and computer science $(n=37,17.37 \%)$, nursing and health $(n=19,8.92 \%)$, education and teaching $(n=17$, $7.98 \%)$, law $(n=4)$, and business $(n=2)$.

\section{Instrumentation}

Co-rumination. The unidimensional Co-Rumination Questionnaire (Rose, 2002) was contextualized and used for the present investigation. This measure evaluates co-rumination through questions exploring different elements of the process. Importantly, this measure has been tested and utilized in a variety of contexts with the most frequent context being among young school-aged children (Rose, 2002). Other researchers have used this measure to test corumination in friendships (Rose et al., 2007) and in college-aged women (Byrd-Craven et al., 2011). Based on those previous studies, the use of this measure to evaluate co-rumination is appropriate for the current investigation, especially given the application to a sample of graduate students. Based on Rose's (2002) analysis, the measure is high in both face and convergent validity and was reliable in their multiple studies (reported $\alpha=.96$ ).

For the present investigation, questions that could not be worded for graduate student friendships were removed yielding 13-items measured on a 5-point Likert scale, and included 
some of the following item domains: (1) how many times respondents discuss their problems, (2) if the respondents discuss their problems instead of focusing on other issues, (3) discussing the same problem repeatedly, (4) speculation about the causes of the problem, (5) consequences of the problems, (6) not understanding the problem, and (7) focus on negative feelings. Overall Cronbach's alpha was .87 for this sample. Mean scores for co-rumination (See Table 1) were calculated for each respondent and utilized in subsequent analyses, similarly to prior research using this measure (Rose, 2002; Rose et al., 2007).

Social Support. In order to evaluate perceived social support, the Scales of Perceived Social Support - nonfamily dimension (SPSS: Macdonald, 1998) was utilized. Although Macdonald (1998) separates social support networks into two dichotomized groups of family and nonfamily (friends and colleagues), only the nonfamily dimension was utilized. This was because the focal social support context of this study was graduate student colleagues. The measure asks respondents to indicate how they feel about others on 28-items using 5-point Likert scales. In prior research, the measure had high reliability (reported between .80 and .94) and is relatively stable over-time with test-retest correlations ranging from .77 to .87 (Macdonald, 1998). Prior testing has established construct and criterion-related validity. For the present investigation, Cronbach's Alpha was calculated at .94. As suggested by Macdonald (1998), all items from this scale were averaged together for a mean total for nonfamily social support (see Table 1).

Emotional Exhaustion. The final measure utilized in this study was the emotional exhaustion dimension from the Maslach Burnout Inventory (MBI: Maslach \& Jackson, 1981; Maslach et al., 1997; Maslach et al., 2001). Since emotional exhaustion is the primary element of the burnout process and the most closely associated with general stress, only that sub-scale was 
used for this study. The MBI is a widely-utilized measure of burnout, with emotional exhaustion being the most commonly used subscale (Maslach et al., 2001). Maslach and colleagues do not argue that all dimensions of burnout are necessary to quantify the presence of burnout; rather, each dimension can be evaluated separate from the others.

The emotional exhaustion sub-scale has high convergent validity (with psychological stress measures) and both a high reported alpha (.90) and test-retest (.80) coefficients (Maslach et al., 1997). The emotional exhaustion subscale provides participants with 9-items related to how often they feel emotional exhaustion (frequency) with response options being 1 (a few times a year) to 6 (every day). The second part of this subscale included the same items from the section on frequency, but asked participants how severe their emotional exhaustion is, ranging from 1 (very mild or barely noticeable) to 7 (very strong or major). Maslach and colleagues argue that frequency and severity are two unique elements of emotional exhaustion and should be evaluated separately; therefore, two mean scores were created for each participant and used in subsequent analyses, as recommended by Maslach et al. (1996). This was also important, given the fact that individuals may report being burnt-out if they have only experienced emotional exhaustion a few times, but very severely. Alternatively, an individual who experiences long-term emotional exhaustion at a moderate level may also encounter the negative side effects of burnout. In this case, a logical argument can be made that severity and frequency are indeed two separate elements of emotional exhaustion and should be analyzed as such. For this investigation, both emotional exhaustion frequency and severity had internal consistency coefficients of .91 and those separate mean scores (see Table 1) were used in subsequent analyses. These two dimensions were highly positively correlated, $r(206)=.90, p<.001$. 


\section{Results}

Many researchers have argued for and used Baron and Kenny's (1986) multi-step causal protocol to determine mediation. However, Hayes (2009) argues, "simulation studies have shown that among the methods for testing intervening variable effects, the causal steps approach is the lowest in power" (p. 410). As Hayes explains, testing these indirect effects through other, more powerful mechanisms serves researchers better than relying on low-power tests (Hayes, 2009; Preacher \& Hayes, 2008). Therefore, with these data, the Preacher and Hayes (2008) SPSS macro called "INDIRECT" was used to compute a bootstrap bias corrected and accelerated confidence interval for the indirect effect (see Hayes, 2009). Correlations, means, and standard deviations for all study variables are reported in Table 1.

Table 1

Descriptive Statistics and Correlations for Study Variables.

\begin{tabular}{|c|c|c|c|c|c|c|}
\hline \multirow[b]{2}{*}{ Measures } & \multirow[b]{2}{*}{ Mean } & \multirow[b]{2}{*}{ SD } & \multicolumn{4}{|c|}{ Pearson Correlations } \\
\hline & & & 1 & 2 & 3 & 4 \\
\hline $\begin{array}{l}\text { 1. Emotional Exhaustion - } \\
\text { Frequency }\end{array}$ & 3.63 & 1.30 & - & $.90 * *$ & $.15^{*}$ & $-.22 * *$ \\
\hline $\begin{array}{l}\text { 2. Emotional Exhaustion - } \\
\text { Severity }\end{array}$ & 3.96 & 1.57 & & -- & $.15^{*}$ & $-.18 * *$ \\
\hline 3. Co-Rumination & 2.93 & .63 & & & -- & $.22 * *$ \\
\hline 4. Social Support & 3.95 & .58 & & & & -- \\
\hline
\end{tabular}

Notes: Two-tailed $* *=$ significant at the $p<.01$ level, $*=$ significant at the $p<.05$ level.

The hypothesis predicted that co-rumination would partially mediate the relationship between social support and both frequency and severity of emotional exhaustion. Therefore, two separate mediation models were tested using the procedure set forth by Hayes (2009). Testing 
these two models separately is important, as both frequency and severity are distinct elements of emotional exhaustion. ${ }^{1}$

The first model (see Figure 1) included average social support scores as the independent variable, reported frequency of emotional exhaustion (how often) as the dependent variable, and average co-rumination score as the mediator variable. The direct effect of social support on frequency of emotional exhaustion had a standardized coefficient of -.62 (SE =.15,p<.001) with the coefficient for the total effect of social support on frequency of emotional exhaustion mediated by co-rumination being $-.50(S E=.15, p<.01)$. All other path coefficients are reported in Figure 1. Utilizing a 95\% level of confidence, a bootstrap method (Hayes, 2009; Preacher \& Hayes, 2008) with 5000 iterations produced a bias corrected and accelerated confidence interval of $.032-.267$. As zero is not included in the confidence interval, it is concluded that the indirect effect is significantly different from zero. Given this information, and the decrease in the direct and total effect coefficients in the $\mathrm{c}$ and c-prime paths, these data do support the prediction in the hypothesis that co-rumination mediates the relationship between social support and frequency of emotional exhaustion. The computed effect size $\left(R^{2}\right)$ for the overall model was $10.1 \%$ (Fairchild, MacKinnon, Taborga, \& Taylor, 2009).

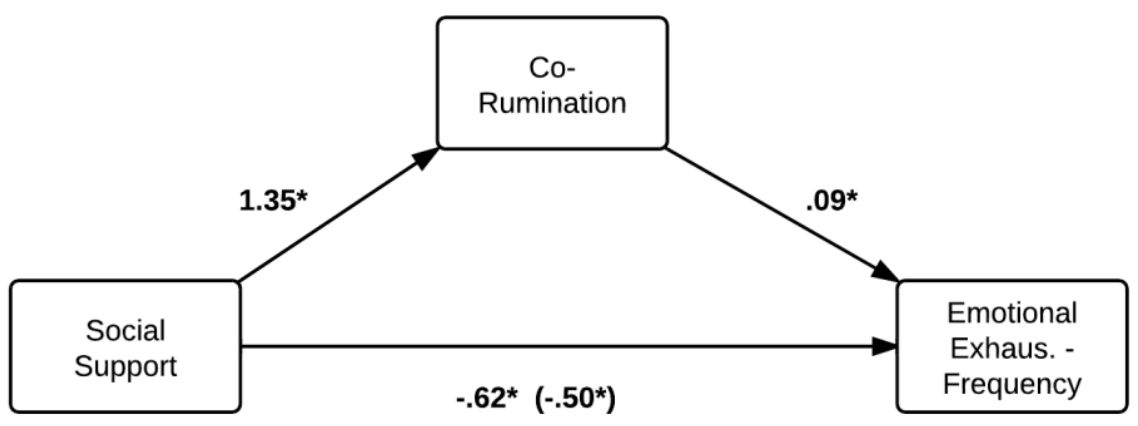

Figure 1. Partial mediation model illustrating co-rumination suppressing the relationship between perceived social support and frequency of emotional exhaustion. All coefficients were significant at the $p<.01$ level. Number on the bottom in parenthesis indicates the total (mediated) effect on emotional exhaustion, with the number outside of the parenthesis as the c-prime path direct effect of social support on emotional exhaustion. Model, $F(2,207)=11.66, p<.001, R^{2}=.10$, Adjusted $R^{2}=.09$. 
While the first model evaluated the frequency of emotional exhaustion (how often individuals felt that they experienced emotional exhaustion), the second model (see Figure 2) explored severity of emotional exhaustion (how severe or intense the emotional exhaustion was) as the dependent variable. All other variables remained the same from the first model. The direct effect of social support on severity of emotional exhaustion had a reported coefficient of -.08 (SE $=.03, p<.001)$ with the coefficient for the total effect of social support on severity of emotional exhaustion mediated by co-rumination being -.07 $(S E=.03, p<.01)$. All other path coefficients are reported in Figure 1. The same bootstrap method reported above produced a bias corrected and accelerated confidence interval of .003-.039. Because of the fact that zero is not included in the confidence interval, it is concluded that the indirect effect is different from zero. Given this information, and the decrease in the direct and total effect coefficients in the c and c-prime paths, these data also support the prediction in the hypothesis for severity of emotional exhaustion, albeit not as strongly as for frequency. The overall computed model effect size $\left(R^{2}\right)$ was $10 \%$ (Fairchild et al., 2009).

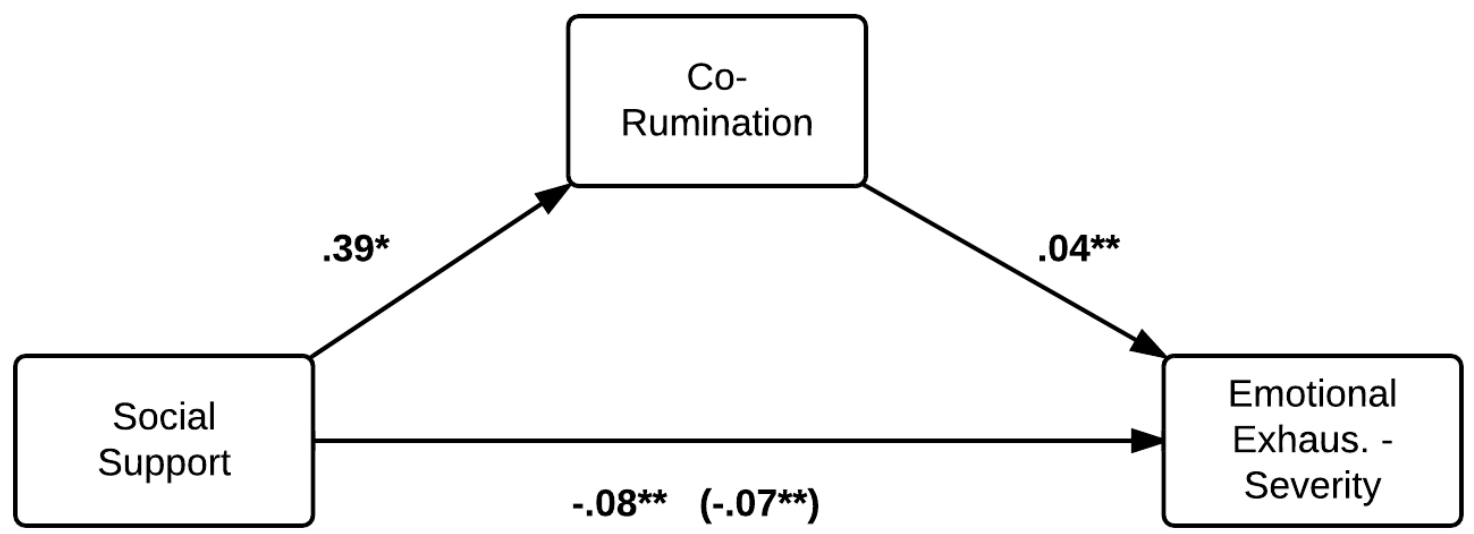

Figure 2. Partial mediation model illustrating co-rumination suppressing the relationship between perceived social support and severity of emotional exhaustion. $*=$ significant coefficient at the $p<.05$, $* *=p<.01$ level. Number on the bottom in parenthesis indicates the total (mediated) effect on emotional exhaustion, with the number outside of the parenthesis as the c-prime path direct effect of social support on emotional exhaustion. Model, $F(2,205)=11.42, p<.001, R^{2}=.10$, Adjusted $R^{2}=.09$. 
Taken together, both models lend support for the notion that co-rumination acts to suppress the relationship between social support and emotional exhaustion. Theoretically speaking, these results indicated that when individuals do not co-ruminate, social support functions to reduce their reports of emotional exhaustion. However, if individuals engage in corumination, the positive benefits of social support on emotional exhaustion are reduced. Based on both models as presented here, the research hypothesis is supported.

\section{Discussion}

This study's primary goal was to determine what effect co-rumination has on the burnout-reducing benefits of social support. The vast majority of research findings indicate that socially-supportive transactions tend to reduce the deleterious effects of emotional exhaustion. However, this study argued that studying a supportive transaction alone is not enough; rather, the content of social support is important. Therefore, by evaluating one negative aspect of perceived supportive transactions, co-rumination, this study has expanded our knowledge of how support works to reduce emotional exhaustion. In fact, the primary finding of this study is that corumination actually suppresses the relationship between social support and emotional exhaustion. Individuals who engage in co-ruminative transactions may be reducing the positive benefits of social support. Graduate students were selected for this study because of their typically close-knit relationship with their colleagues coupled with their constant state of elevated stress, creating an environment which is conducive to co-rumination.

The hypothesis posited that co-rumination would partially mediate the relationship between social support and emotional exhaustion. Based on prior research, social support is typically negatively associated with emotional exhaustion, the stress dimension of burnout (see Cohen \& Wills, 1985). In fact, both frequency and severity of emotional exhaustion were 
negatively correlated with social support (see Table 1). While simply demonstrating that social support is negatively associated with elements of burnout is rather banal, this study explored the specific content of social support. That is, those supportive transactions which are indicated by regular and constant negative talk about an issue are indicative of co-rumination. Indeed, recent literature has found positive relationships between co-rumination and emotional exhaustion, findings that were replicated in these data (see Table 1).

When individuals co-ruminate, they are engaging in a supportive transaction. However, that element of co-rumination is suppressing the positive benefits of social support on stressrelated outcomes. This was seen in both mediation models, given the coefficient reduction from direct to total effects. Co-rumination works to increase emotional exhaustion scores among these participants, in spite of any reduction in emotional exhaustion from social support. This is similar to the research on emotional contagion, whereby members experience the expressed emotion of others, based strictly on their dyadic communication (Hatfield et al., 1993). From a strictly psychological perspective, the blunted effect of positive social support makes sense - a finding that may replicate itself with physiological outcomes.

Within the context of graduate school, when these graduate students engaged in corumination they reported greater level of emotional exhaustion, which may also be attributed to the fact that they must not only manage their personal problems, but also those of their colleagues. This may explain why the mediation effect of co-rumination on frequency of emotional exhaustion was stronger than the effect on severity. Like social support, co-rumination is an interactive process. For these data, it was not entirely clear if the respondent who felt greater emotional exhaustion was the primary recipient or sender of co-ruminative messages. However, an argument could be made that just being party to a co-ruminative interaction is 
enough to potentially increase burnout, even if the issue is not particularly salient to that person. The idea here is that an interaction, with the best intentions of being socially supportive, could easily turn into a session of co-rumination. In this sense, co-rumination may be more insidious than originally conceptualized by prior researchers (Rose, 2002; Rose, Carlson, \& Waller, 2007; Haggard, Robert, \& Rose, 2011). Conversely, engaging in frequent co-ruminative interactions may instill a more fleeting sense of emotional exhaustion than severe, causing the individual to be emotionally exhausted about that interaction, but not enough to have that level of burnout spill over to other aspects of his or her life. However, regardless of the individual's role in engaging in co-rumination, the mere fact he or she did so was enough to reduce much of the positive effects of social support on emotional exhaustion for this sample, which is quite telling.

Ascertaining a more complete understanding of social support transactions is very important, especially if organizations are aware that social support can reduce emotional exhaustion (Heaphy \& Dutton, 2008). This is even more important when engagement at work has been the typical prescription given to an emotionally-exhausted workforce (Maslach et al., 2001; Schaufeli \& Bakker, 2004). Burnout researchers have been articulating complex arguments and presenting detailed theoretic models calling for increases in social support in the workforce; however, those employees who are already emotionally-exhausted may already be co-ruminating with their colleagues, thereby exacerbating the effects of emotional exhaustion. Indeed, the findings in this study may be isolated to graduate students only, but given the job demands, job requirements, and nature of graduate student work, these findings may be applicable to a variety of occupations. These results call into question the conventional wisdom that social support is beneficial to both the workplace and the individual. Conversely, the content 
of those supportive messages may be just as important, if not more important, as engaging in a supportive transaction.

\section{Applications}

Practically speaking, graduate program directors may be well advised to teach effective social support skills, such as providing emotional and instrumental support to each other while not dwelling on particular problems. Suran and Sheridan (1985) suggest that graduate students should be trained on the material aspects of their jobs as well as be provided with realistic assessments of the rigors of graduate school. Furthermore, universities and departments may want to consider offering graduate students a realistic job preview (RJPs) program. These RJPs might include accurate presentations of their future research, teaching, and academic requirements; meetings with existing graduate students without faculty present; shadowing programs with existing students; and any other mechanism to show the potential student both the work and demands associated with being a graduate student at that institution. Finally, to guard against co-rumination, academic departments may want to institute policies that make grievances easier to file and provide open lines of communication between administration, faculty, and graduate students. Some institutions even have regular group-based grievance meetings, where all students come together for an afternoon and develop a list of issues that the department chair (or other administrator) can address throughout the year. Co-rumination, then, becomes harder to engage in when there are fewer issues to ruminate about and when the content of social support begins to focus strictly on peer-mentoring and emotional support from friends and colleagues.

\section{Limitations and Directions for Future Research}

There were some limitations to the present investigation. One primary limitation was the fact that this project was not conducted over any length of time. Future research projects should 
consider the longitudinal effects of co-rumination and social support on emotional exhaustion, thereby providing support for causal relationships. Other dependent variables may also be useful in ascertaining the suppressive effects of co-rumination including global stress, organizational commitment, organizational culture, and physiological outcomes. Since this study focused on one particular context, expanding this research into other contexts and organizations may be particularly useful. Future projects may also want to evaluate the other dimensions of burnout to see if the same mediator relationships hold true for cynicism and inefficacy as it did for emotional exhaustion. Perhaps exploring communicator roles (i.e., who is the initiator or recipient) in co-ruminative transactions would also be useful in understanding this phenomenon, particularly by evaluating those individuals who tend frequently to initiate co-rumination interactions. Finally, triangulation through content analytic, qualitative, and/or ethnographic inquiry may assist in painting a more holistic picture of the types of communicative messages that occur during co-ruminative transactions.

\section{Conclusions}

The results of this study inform us that (a) co-rumination does mediate the relationship between social support and emotional exhaustion, (b) focusing attention on the content of social support may be an important element of future social support studies, and (c) the buffering effects of social support may be complicated by the types of supportive messages, especially if those messages include excessive problem-talk. This study is only the start to gaining a better understanding of how specific interactions within a social support framework can either support or potentially harm individuals and organizations. While research on social support has been extensive, the entire picture may still not be clear. Further inquiry into how excessive problem- 
talk can modify the positive benefits of social support will help researchers in pinpointing the most beneficial types of socially-supportive messages and interventions. 


\section{References}

Baron, R. M., \& Kenny, D. A. (1986). The moderator-mediator variable distinction in social psychological research: Conceptual, strategic, and statistical considerations. Journal of Personality and Social Psychology, 51, 1173-1182. doi: 10.1037/0022-3514.51.6.1173

Burleson, B. R., Albrecth, T., Goldsmith, D. J., \& Sarason, I. G. (1994). Introduction to the Communication of Social Support. In B. R. Burleson, T. Albrecth \& I. G. Sarason (Eds.), Communication of Social Support: Messages, Interactions, Relationships, and Community (pp. xi-xxx). Thousand Oaks, CA: Sage.

Byrd-Craven, J., Geary, D. C., Rose, A. J., \& Ponzi, D. (2008). Co-ruminating increases stress hormone levels in women. Hormones and Behavior, 53, 489-492. doi: 10.1016/j.yhbeh.2007.12.002

Byrd-Craven, J., Granger, D. A., \& Auer, B. J. (2011). Stress reactivity to co-rumination in young women's friendships: Cortisol, alpha-amylase, and negative affect focus. Journal of Social and Personal Relationships, 28, 469-487. doi: 10.1177/0265407510382319

Chandola, T., Brunner, E., \& Marmot, M. (2006). Chronic stress at work and the metabolic syndrome: Prospective study. BMJ, 332, 521-525. doi: 10.1136/bmj.38693.435301.80

Cohen, S., Underwood, L., \& Gottlieb, B. H. (2000). Social support measurement and intervention: A guide for health and social scientists. Oxford ; New York: Oxford University Press.

Cohen, S., \& Wills, T. A. (1985). Stress, social support, and the buffering hypothesis. Psychological Bulletin, 98, 310-357. doi: 10.1037/0033-2909.98.2.310 
Dickerson, S. S., \& Kemeny, M. E. (2004). Acute stressors and cortisol responses: A theoretical integration and synthesis of laboratory research. Psychological Bulletin, 130, 355-391. doi: 10.1037/0033-2909.130.3.355

Eller, N. H., Netterstrøm, B., Gyntelberg, F., Kristensen, T. S., Nielsen, F., Steptoe, A., et al. (2009). Work-related psychosocial factors and the development of ischemic heart disease: A systematic review. Cardiology in Review, 17, 83-97. doi: 10.1097/CRD.0b013e318198c8e9

Fairchild, A., MacKinnon, D., Taborga, M., \& Taylor, A. (2009). R2 effect-size measures for mediation analysis. Behavior Research Methods, 41(2), 486-498. doi: 10.3758/brm.41.2.486

Haggard, D. L., Robert, C., \& Rose, A. J. (2011). Co-rumination in the workplace: Adjustment trade-offs for men and women who engage in excessive discussions of workplace problems. Journal of Business Psychology, 26, 27-40. doi: 10.1007/s10869-010-9169-2

Hammer, L. B., Grigsby, T. D., \& Woods, S. (1998). The conflicting demands of work, family, and school among students at an urban university. The Journal of Psychology, 132(2), 220-226. doi: 10.1080/00223989809599161

Hatfield, E., Cacioppo, J. T., \& Rapson, R. L. (1993). Emotional contagion. Current Directions in Psychological Science, 2, 96-99. doi: 10.1111/1467-8721.ep10770953

Hayes, A. F. (2009). Beyond Baron and Kenny: Statistical mediation analysis in the new millennium. Communication Monographs, 76(4), 408-420. doi:

$10.1080 / 03637750903310360$ 
Heaphy, E. D., \& Dutton, J. E. (2008). Positive social interactions and the human body at work: Linking organizations and physiology. Academy of Management Review, 33, 137-162. doi: $10.2307 / 20159380$

Heins, M., Fahey, S. N., \& Leiden, L. I. (1984). Perceived stress in medical, law, and graduate students. Journal of Medical Education, 59, 169-179.

Hoffman, M. F., \& Cowan, R. L. (2008). The meaning of work/life: A corporate ideology of work/life balance. Communication Quarterly, 56, 227-246. doi: $10.1080 / 01463370802251053$

Lundberg, C. A., McIntire, D. D., \& Creasman, C. T. (2008). Sources of social support and selfefficacy for adult students. Journal of College Counseling, 11, 58-72. doi: 10.1002/j.2161-1882.2008.tb00024.x

Macdonald, G. (1998). Development of a social support scale: An evaluation of psychometric properties. Research on Social Work Practice, 8, 564-576. doi:

$10.1177 / 104973159800800505$

Maslach, C., \& Jackson, S. E. (1981). The measurement of experienced burnout. Journal of Occupational Behaviour, 2, 99-113. doi: 10.1002/job.4030020205

Maslach, C., Jackson, S. E., \& Leiter, M. P. (1996). Maslach burnout inventory manual (3rd ed.). Mountain view, CA: CPP, Inc.

Maslach, C., Jackson, S. E., \& Leiter, M. P. (1997). Maslach burnout inventory. In C. P. Zalaquett \& R. J. Wood (Eds.), Evaluating Stress: A book of resources (pp. 191-218). London: Scarecrow Press.

Maslach, C., Schaufeli, W. B., \& Leiter, M. P. (2001). Job burnout. Annual Review of Psychology, 52, 397-422. doi: 10.1146/annurev.psych.52.1.397 
Miller, K. I., Stiff, J. B., \& Ellis, B. H. (1988). Communication and empathy as precursors to burnout among human service workers. Communication Monographs, 55(3), 250-265. doi: 10.1080/03637758809376171

Pierce, G. R., Sarason, B. R., \& Sarason, I. G. (1996). Handbook of social support and the family. New York: Plenum Press.

Preacher, K., \& Hayes, A. F. (2008). Asymptotic and resampling strategies for assessing and comparing indirect effects in multiple mediator models. Behavior Research Methods, 40(3), 879-891. doi: 10.3758/BRM.40.3.879

Pruessner, J. C., Hellhamer, D. H., \& Kirschbaum, C. (1999). Burnout, perceived stress, and cortisol responses to awakening. Psychosomatic Medicine, 61, 197-204. doi: 00333174/99/6102-0197

Rees, T., \& Freeman, P. (2007). The effects of perceived and received support on selfconfidence. Journal of Sports Sciences, 25, 1057-1065. doi: $10.1080 / 02640410600982279$

Rose, A. J. (2002). Co-rumination in the friendships of girls and boys. Child Development, 73(6), 1830-1843. doi: 10.1111/1467-8624.00509

Rose, A. J., Carlson, W., \& Waller, E. M. (2007). Prospective associations of co-rumination with friendship and emotional adjustment: Considering the socioemotional trade-offs of corumination. Developmental Psychology, 43(4), 1019-1031. doi: 10.1037/0012$\underline{1649.43 .4 .1019}$

Sandelands, L. E., \& Boudens, C. J. (2000). Feeling at work. In S. Fineman (Ed.), Emotion in Organizations (2nd ed., pp. 46-63). London: Sage. 
Schaufeli, W. B., \& Bakker, A. B. (2004). Job demands, job resources, and their relationship with burnout and engagement: A multi-sample study. Journal of Organizational Behavior, 25, 293-315. doi: 10.1002/job.248

Shirom, A., Toker, S., Alkaly, Y., Jacobson, O., \& Balicer, R. (2011). Work-based predictors of morality: A 20-year follow-up of healthy employees. Health Psychology, 30(3), 268-275. doi: $10.1037 / \mathrm{a} 0023138$

Smith, S. L. (1999). Job burnout is a hot topic. Organizational Hazards, 61, 31-32.

Suran, B. G., \& Sheridan, E. P. (1985). Management of burnout: Training psychologists in professional life span perspectives. Professional Psychology: Research and Practice, 16, 741-752. doi: $\underline{10.1037 / 0735-7028.16 .6 .741}$

Uchida, K., \& Yamasaki, K. (2008). Social support mediating between coping by emotional expression and depression. Psychological Reports, 102, 144-152. doi: 10.2466/pr0.102.1.144-152

Uchino, B. N. (2004). Social support and physical health: Understanding the leaht consequences of relationships. New Haven, CT: Yale UP.

Zimmermann, S., \& Applegate, J. L. (1994). Communicating social support in organizations. In B. R. Burleson, T. Albrecth \& I. G. Sarason (Eds.), Communication of social support (pp. 50-69). Thousand Oaks, CA: Sage. 


\section{Footnote}

${ }^{1}$ A composite emotional exhaustion score was evaluated in a separate model by avererging the z-scores (to account for scaling differences) for both frequency and severity. The nature of the two models reported in the results section do not differ when evaluating emotional exhaustion as one outcome variable, $R^{2}=.082$, Adjusted $R^{2}=.073, F(2,207)=9.28, p<.001$, bootstrap (5000 iterations, 95\% confidence level) bias corrected and accelerated confidence interval $=.0179-.1785$. Therefore, the two models using frequency and severity as separate outcomes are reported herein, as suggested by the authors of the original burnout inventory. 